\title{
BROCCHINIA REDUCTA LIGHT PREFERENCES
}

\author{
BARRY RICE • P.O. Box $72741 ・$ Davis, CA 95617•USA・barry@sarracenia.com
}

Keywords: cultivation: Brocchinia reducta, lighting.

Brocchinia reducta is one of those species of plants that has, at best, mixed support by carnivorous plant growers. The plant's problem is that it is usually relegated to the ranks of semicarnivory, or even noncarnivory. This is because it apparently does not produce its own digestive enzymes, nor does it seem particularly specialized for capturing insects. In fact, most photographs of the plant in cultivation show that it looks like a fairly unimpressive, urn-shaped bromeliad (see Figures 1,2).

I have grown this plant for nearly a decade, and agree that in most settings it is indeed a rather boring bromeliad. I do not even maintain plants in my own collection, instead I grow the plants at the University of California (Davis) collections. It is trivial to grow-it does not seem to care too much about the soil medium, and keeping it in a 1:1:1 sand:perlite:peat mix or 3:1 perlite:sphagnum mix and temperatures anywhere in the range $15-35^{\circ} \mathrm{C}\left(60-95^{\circ} \mathrm{F}\right)$ works just fine. I provide the plants with purified water, which I pour directly into the pitcher urn. I do not fertilize them.

Typically a plant matures within a few years, produces an inflorescence, and then dies. As it rots away, two or more new shoots emerge from the plant-these are called pups by bromeliad growers - and they can be separated when the parent plant rots away. Usually the pups are produced on the sides of the parent plant, but very occasionally they emerge from the center of the urn. Equally rarely, a tiny pup may emerge from the soil, spaced a few $\mathrm{cm}$ away from the plant by a slender stolon and looking very much like a seedling. All my plants are genetically identical, as they are vegetatively produced descendents of a single parent plant. As such, I have not had success self pollinating them.

I have never seen or photographed this plant in the wild, so when I wrote my book I relied upon Stew McPherson for a few images. Looking at the images he sent to me, I was struck by how plants in the wild looked so different from images of plants in cultivation. Wild plants are tall, narrowly tubular, yellow-green, and very strange looking. They did not look at all like the conventional dark-green, urn-shaped bromeliad I had become accustomed to by looking at plants in my own cultivation, or for that matter the unremarkable plants in anyone else's cultivation!

I wondered -is it possible that the clones in cultivation were some boring strain that did not look as interesting as the plants in the wild? Or was it possible that they would assume the vastly more interesting form, as expressed by wild plants, if they were grown better? I guessed that the most likely error was in illumination - after all, these are plants that grow in extremely high light levels on the tops of tepuis and in the Gran Sabana. Recently, at the University of California (Davis), a new greenhouse was built for our Botanical Conservatory. The new facility is warm and extremely bright, and we are still learning what plants grow best there. We have found that Dionaea and Drosophyllum love it there, but that it is far too bright for Nepenthes. I wondered how our boring Brocchinia might survive there. One of our plants had just flowered, and was producing three pups - two laterally and one from the urn center. I put the pot in the bright greenhouse and watched the pups develop over the next year.

I was amazed at the results. While the plants in our main greenhouse still look like boring bromeliads, the plants in our bright greenhouse look more like wild plants! They are yellowgreen, and extremely tall and narrow (see Figure 3). In fact, they are very interesting looking plants. I suspect that if everyone grew them under extremely bright, full sun conditions, they might have much more natural looking plants, and this bromeliad might get a little more respect and enthusiasm from the carnivorous plant community. 


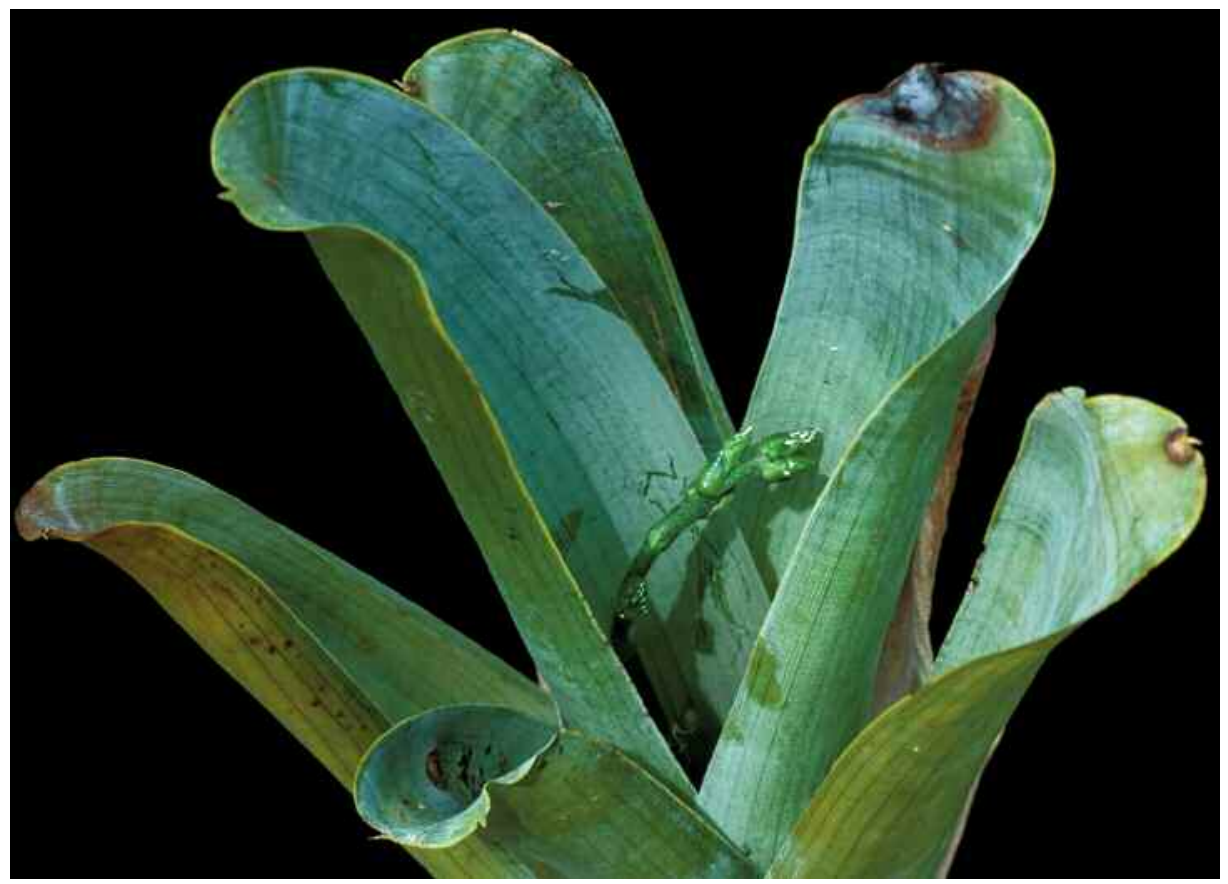

Figure 1: Brocchinia reducta grown under fairly low light levels. The foliage is bright green and spreading. Even though unnatural in appearance, the plant is producing an inflorescence.

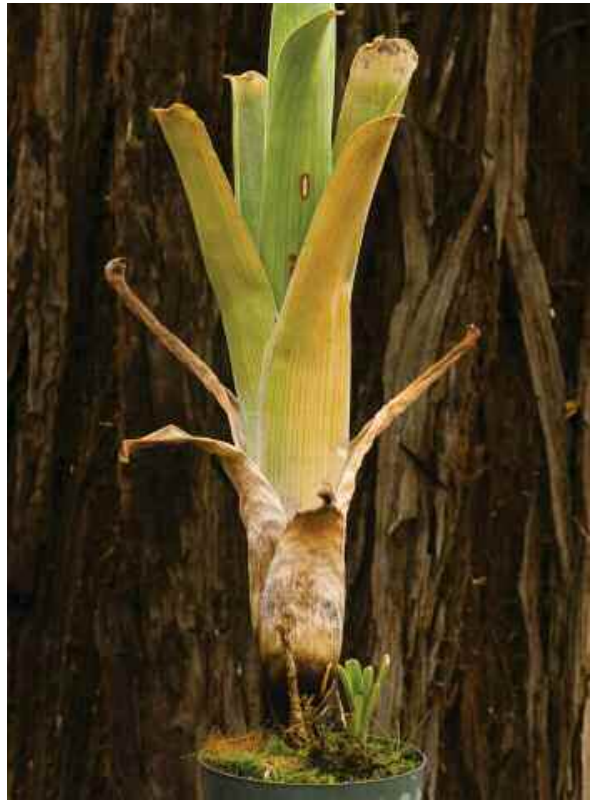

Figure 2: Brocchinia reducta grown under higher, but still inadequate light levels. The foliage is somewhat more tightly cylindrical and yellow.

Volume 38 March 2009

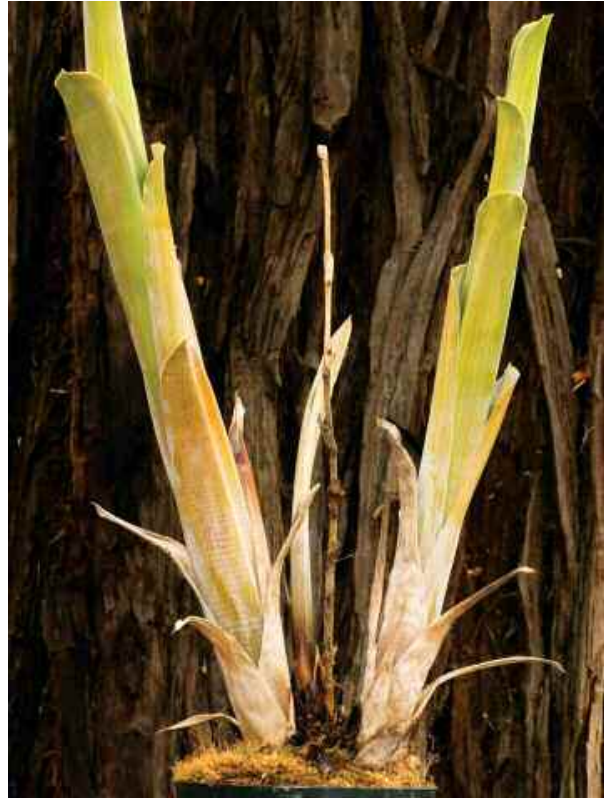

Figure 3: Brocchinia reducta grown under high light levels. The pot contains the decaying, dead, parent plant and its old inflorescence, two lateral plantlets, and a developing central plantlet. 